\section{THE COLLECTED PAPERS OF ST. MARK'S HOSPITAL.}

H. K. Lewis \& Co. 1935. Price 30/-.

The collected papers of St. Mark's Hospital, London, are published to commemorate the centenary of the hospital, and to perpetuate the memory of the founder, Frederick Salmon, who also held the post of surgeon for 22 years.

The work opens with the appeal issued a century ago on behalf of the hospital, then referred to as the "infant charity," and a history of the institution from its foundation until the present day.

The bulk of the work comprises a collection of papers published by past and present members of the staff, and very properly commences with a paper by Salmon on Strictures of the Rectum. The keeness of the surgeon is exemplified by his method of keeping in touch with a hospital patient,by the payment of sixpence a month prorided the patient reported at his house. This is probably the first recorded FollowUp Department!

The more modern papers form an admirable summary of rectal surgery of the present day, and include chapters on anæsthesia and pathology. The work is excellently produced, and the medical committee are to be congratulated on the production of a volume of both historical and practical interest.

\section{CLINICAL METHODS. (TENTH EDITION).}

By Robert Hutchison, M.D., F.R.C.P., and Donald Hunter, M.D., F.R.C.P. Cassell \& Co., Ltd. 1935. Price 12/6.

There are very few medical text-books which can boast a life such as that of "Clinical Methods" originally from the pens of Robert Hutchison and Harry Rainy in 1897. Since then it has passed through ten.editions and has been reprinted twenty-four times; so that practically every year during the long period of almost 40 years a call has been made on the publishers for a fresh supply. This speaks for the excellence of the publication and the important place that it occupies among medical text books. Indeed, there must be hardly a medical man to-day who in his time has not possessed a copy from which he learned the principles of physical diagnosis.
This, the tenth edition, is the conjoint work of Robert Hutchison (one of the original authors) and Donald Hunter, and will if anything enhance the reputation of its predecessors. Much out-of-date teaching has been removed and recent additions to the methods of investigating disease have been incorporated. We think however, that surely the time has come to dispense with long discussions of superficial and deep cardiac dulness, as no one nowa-days attempts such a differentiation. In the section on gastric analysis we are surprised that no mention is made of alcohol as a test meal or of the use of histamin to stimulate gastric secretion. And further, we would have thought that in a text-book dealing with modern methods of diagnosis Kahn's test for evidence of the luetic infection should find a place. In the consideration of urinary function surely mention should be made of Calvert's modification of the urea concentration test and of the correlation of this with the bloodurea.

What one misses most in this volume is some expression of opinion regarding the real value of many of the tests described. To meet this would require a considerable increase in the size of the book and no doubt the authors intend it to be simply a compendium of the various "side-room" and bed-side investigations of disease and as such it can be most confidently recommended.

\section{HEAD INJURIES.}

By L. Bathe Rawling. Oxford University Press. London: Humphrey Milford. 1934. Price $7 / 6$.

This is a readable little book giving in outline the chief features of acute head injuries and their sequelæ. It would appear that the author is not altogether an advocate of modern methods of investigation; thus he confesses himself unconvinced that manometry is necessary and that the pressure of the cerebro-spinal fluid can be estimated within reasonable limits without the use of a manometer. Such a doctrine is not only reactionary but incorrect. The chapter on the early and late complications is scarcely adequate, and no description is attempted of the all important subject of the " post-concussional sundrome." 